\title{
Projeto Bandeira Científica: uma Extensão Interdisciplinar com Impactos na Formação em Psicologia
}

\author{
Adriana Marcondes Machado ${ }^{1}$ \\ ${ }^{1}$ Universidade de São Paulo, SP, Brasil. \\ Fernanda de Jesus Ligeiro Braga ${ }^{2}$ \\ ${ }^{2}$ Universidade Federal de São Paulo, SP, Brasil. \\ Rodolfo Luis Almeida Maia ${ }^{1}$ \\ ${ }^{1}$ Universidade de São Paulo, SP, Brasil.
}

\author{
Débora Song Shimba ${ }^{3}$ \\ ${ }^{3}$ Universidade Estadual de Campinas, SP, Brasil. \\ Gabriel Rodrigues Mardegan ${ }^{4}$ \\ ${ }^{4}$ Fundação Oswaldo Cruz, RJ, Brasil. \\ Bruna Caroline Oliveira de Souza ${ }^{2}$ \\ ${ }^{2}$ Universidade Federal de São Paulo, SP, Brasil.
}

Jéssica Aparecida da Silva ${ }^{1}$

${ }^{1}$ Universidade de São Paulo, SP, Brasil.

\begin{abstract}
Resumo: Trata-se de um relato de experiência cujo objetivo é apresentar e descrever o projeto de extensão acadêmica em saúde Bandeira Científica, com foco na importância de projetos dessa natureza para a formação em Psicologia, sobretudo no que se refere a sua dinâmica interdisciplinar. O projeto foi criado na década de 1950, na Faculdade de Medicina da Universidade de São Paulo, e hoje congrega estudantes de 12 cursos da USP. Apresentamos como se organiza o projeto e os espaços interdisciplinares criados, e em seguida elegemos quatro situações a fim de ilustrar e discutir como essas experiências ressoam na formação em Psicologia. O artigo evidencia o diferencial desse projeto para o estudante de Psicologia: nele ocorrem reflexões sobre temas e situações a que pouco se tem acesso no currículo básico, e são desenvolvidos saberes em diálogo com outras áreas do conhecimento, ressaltando o valor do caráter interdisciplinar e interprofissional para a construção das práticas do projeto e para a formação dos estudantes.

Palavras-chave: Educação Interprofissional, Saúde, Interdisciplinaridade, Políticas Públicas.
\end{abstract}

\section{Bandeira Científica Project: an Interdisciplinary Extension Course with Impacts on the Professional Training in Psychology}

\begin{abstract}
This article is an experience report that introduces and describes the project of health academic extension called Bandeira Cientifica, focusing on the importance of projects of this nature to the academic education and professional formation of psychologists following an interdisciplinary dynamic. This project was created in 1950 in the Faculty of Medicine of the University of São Paulo and currently includes 12 different graduation courses. We present how the project is organized and the interdisciplinary spaces that were created, in addition we elect four situations to illustrate and discuss how these experiences impact professional training in Psychology. This article reveals the differential aspects of a project like this to Psychology students: reflections and discussions related to themes and situations that students barely have access to during the basic curriculum and knowledge related to other professional fields is possible to be developed, highlighting the importance of interdisciplinary and interprofessional characters during the construction of the project and during the professional education of the participant students.
\end{abstract}

Keywords: Interprofessional Education, Health, Interdisciplinarity, Public Policies. 


\title{
Proyecto Bandeira Científica: una Extensión Interdisciplinaria con Efectos en la Formación en Psicología
}

\begin{abstract}
Resumen: Se trata de un relato de experiencia cuyo objetivo es presentar y describir el proyecto de extensión académica en salud, Bandeira Científica, enfocándose en la importancia de proyectos de esa naturaleza para la formación en Psicología, sobre todo en lo que se refiere a su dinámica interdisciplinaria. El proyecto comenzó en la década de 1950, en la Facultad de Medicina de la Universidad de São Paulo (USP), y actualmente se compone por estudiantes de 12 cursos de la USP. Primero, presentamos cómo el proyecto se organiza y cuáles son los espacios interdisciplinarios creados, en seguida elegimos cuatro situaciones para ilustrar y discutir cómo esas experiencias resuenan en la formación en Psicología. El artículo evidencia los diferenciales de ese proyecto para el estudiante de Psicología: las reflexiones que se dan sobre temas y situaciones a las cuales se tienen poco acceso en el plan de estudios y el desarrollo de saberes con otras áreas del conocimiento, resaltando el valor del carácter interdisciplinario e interprofesional para la construcción de las prácticas del proyecto y la formación de los estudiantes.
\end{abstract}

Palabras clave: Educación Interprofesional, Salud, Interdisciplinariedad, Políticas Públicas.

\section{Introdução}

O Bandeira Científica é um projeto acadêmico de extensão universitária com foco na área da saúde. Se iniciou em 1957 a partir da iniciativa de alunos da Faculdade de Medicina da Universidade de São Paulo (FMUSP), com ênfase nos aspectos de ensino e pesquisa, foi interrompido em 1969, em decorrência dos atravessamentos políticos da época, e retomado em 1998. Desde então é realizado anualmente, desenvolvendo atividades de atenção direta à saúde individual e coletiva, além de práticas que visam a melhoria das condições organizacionais e estruturais relacionadas à saúde do município parceiro.

O projeto tem como objetivo desenvolver parcerias de duração anual entre cursos da Universidade de São Paulo e municípios com Índice de Desenvolvimento Humano (IDH) considerado médio (entre 0,5 e 0,7) e população entre 20 e 30 mil habitantes, com o objetivo de contribuir para o desenvolvimento da saúde na região. A cada ano, um novo grupo de participantes ingressa no projeto e estabelece uma parceria com um município diferente. Na edição do projeto de fevereiro de 2016 a julho de 2017, estiveram envolvidos alunos, funcionários e professores de 12 cursos da USP, sendo eles: Medicina; Medicina Veterinária; Fisioterapia;
Fonoaudiologia; Terapia Ocupacional; Psicologia; Engenharia Civil, Mecânica e Ambiental; Odontologia; Farmácia e Bioquímica; Nutrição; Saúde Pública; e cursos da Faculdade de Economia, Administração, Contabilidade e Atuária (FEA), assim como a empresa júnior Medicina Jr. Participaram 216 pessoas: 59 profissionais e 157 estudantes, sendo 11 alunos do curso de graduação em psicologia ${ }^{1}$.

As ações têm como norteadores os princípios e diretrizes do Sistema Único de Saúde (SUS) - universalidade, integralidade e equidade (Brasil, 1988; Brasil, 1990) -, utilizando-se de conceitos e dispositivos de cuidado associados aos campos da atenção primária à saúde e da saúde coletiva. São realizadas atividades de promoção da saúde e assistenciais a partir de parcerias estabelecidas, sobretudo, com Unidades Básicas de Saúde (UBS) e Núcleos de Apoio à Saúde da Família (NASF) das cidades em que o projeto é realizado. Além desses serviços, o projeto cada vez mais se articula com as áreas da assistência social e da educação, objetivando ampliar o olhar sobre o contexto da cidade parceira e sobre os indivíduos e grupos ali existentes, com foco na integralidade do cuidado.

Entendemos saúde como um direito fundamental do ser humano, que não se resume à ausência de

${ }^{1}$ O Instituto de Psicologia participa do projeto desde 2006. Inicialmente, a professora Ianni Scarcelli ocupava a coordenação da área da Psicologia no projeto. Atualmente, essa função é dividida com a professora Adriana Marcondes Machado, docente no mesmo Instituto. 
doença (Organização Mundial da Saúde, 1946). Nesse sentido, alinhamo-nos à ideia de que o processo saúde-doença é um processo que transcende o bem-estar físico, reconhecendo que nele há atravessamentos de ordem subjetiva, social, econômica, cultural e ambiental (Dimenstein \& Macedo, 2012). Portanto, a garantia à saúde deve ir além da esfera das atividades clínico-assistenciais, incluindo também as políticas públicas de diversos setores - educação, assistência social, cultura, mobilidade -, a articulação da rede de atenção, a análise do processo de trabalho dos usuários e trabalhadores e a valorização das singularidades dos atores envolvidos (Brasil, 2007). Tendo isso em vista, o Bandeira Científica busca um diálogo com a rede de atenção - entendendo que esta é constituída não somente pelos equipamentos formais de saúde pública, mas principalmente pelos atores que a produzem (usuários, profissionais e gestores) - e com as iniciativas comunitárias do município para potencializar as ações tanto do projeto quanto do próprio município.

Em relação ao ensino, o Bandeira Científica, ao se configurar como um projeto de extensão universitária, propicia uma experiência de exercer práticas em saúde de maneira multi e interprofissional. É valorizado, além dos preceitos técnicos, o desenvolvimento de ações que atendam os interesses públicos de forma ética e humanística, visando à formação de profissionais que se tornem mais conscientes das realidades, particularidades e necessidades regionais (Ceccim \& Feuerwerker, 2004). Com a integração entre ensino, serviços e comunidade, o projeto Bandeira Científica dialoga com a gestão da cidade, os profissionais e a população, avalia as condições locais, e aponta reflexões e sugestões de possibilidades de atuação de médio e longo prazo para um processo de transformação gradual.

Congregando alunas e alunos de diversas áreas da saúde e, também, das chamadas "áreas técnicas" (FEA, Medicina Jr. e Engenharias Civil, Ambiental e Mecânica), o Bandeira Científica tem na interdisciplinaridade um dos seus maiores potenciais de aprendizagem e atuação. Suas atividades provocam reflexões e discussões sobre os desafios do trabalho em equipe envolvendo diferentes áreas, tanto no Bandeira, especificamente, quanto no trabalho em saúde em geral.

São poucas as oportunidades, no decorrer da graduação em psicologia na USP, de convívio e compartilhamento de experiências com outras áreas de formação: as aulas e os estágios, de um modo geral, ocorrem em ambientes e instituições que concentram pessoas de uma única área, configurando uma formação predominantemente uniprofissional (Luz, 2009). O projeto Bandeira Científica surge como uma oportunidade de os estudantes elaborarem conjuntamente reflexões e soluções para os desafios que emergem nas suas diferentes etapas, sendo demandado dos participantes que se envolvam com questões para além de sua área de estudo. O contato com outras áreas enriquece a formação em Psicologia, uma vez que o contexto interdisciplinar apresenta aos estudantes as similaridades e as diferenças entre os diversos saberes e práticas, propiciando percepções mais precisas sobre as funções de cada área no desenvolvimento das ações em saúde.

No campo da saúde pública, o saber e a ação interdisciplinar são ainda mais potentes e necessários devido à complexidade de seu objeto, que não se reduz a saberes técnico-científicos (Gomes \& Deslandes, 1994). O debate sobre concepções ampliadas de saúde desafia aqueles que pesquisam e/ou trabalham na área a pensar políticas públicas de modo integral e integrado (Dejours, 1986). A saúde, além de um direito fundamental, pensada como movimento constante na busca de bem-estar e de ressignificação da vida nas mais variadas dimensões, exige a perspectiva de diversos saberes para que o campo da saúde se construa (Organização Mundial da Saúde, 1946).

Muito se discute sobre os conceitos de interdisciplinaridade, multidisciplinaridade e transdisciplinaridade no campo da saúde coletiva e sobre as diferenças entre esses paradigmas (Luz, 2009). Optamos por adotar neste trabalho o termo interdisciplinaridade por fazer referência a uma intersecção possível de alguns aspectos conceituais e metodológicos no encontro entre diferentes áreas do saber. Porém, entendemos que uma análise mais pormenorizada dos momentos do projeto poderia indicar a presença também dos outros dois paradigmas supracitados.

A interdisciplinaridade, enquanto conceito e posição política, tomou corpo a partir da década de 1960, visando transcender o saber fragmentado fruto da hiperespecialização das disciplinas científicas. Esse movimento propôs o resgate da totalidade do conhecimento e da humanização de sua aplicação, e, consequentemente, a crítica do seu fazer fragmentado (Japiassu, 1976). O conceito de interdisciplinaridade não nega a importância das especialidades, mas reitera o valor 
fundamental de sua articulação. O desafio interdisciplinar passa pelo diálogo entre as disciplinas, o que é diferente da justaposição de conhecimentos impermeáveis entre si (Gusdorf, 1976). Existe uma coexistência paradigmática entre a interdisciplinaridade, a multidisciplinaridade - caracterizada pela "soma de 'olhares' e métodos aportados pelos profissionais das diferentes disciplinas ou práticas (normativas e discursivas)" (Luz, 2009, p. 307) - e a transdisciplinaridade - proposta que indica a cooperação entre distintos saberes a partir da eleição de um objeto comum de investigação (Luz, 2009). Com diferenças no que tange ao tipo e grau de interação entre as disciplinas, tais propostas promovem a abertura para trocas ocorrerem entre áreas do saber. Essa discussão alcançou o campo do ensino e da prática profissional em saúde, gerando reflexões sobre o trabalho em equipe e ações colaborativas entre as variadas profissões neste âmbito.

Compreendendo que a disciplinaridade se refere às disciplinas ou áreas do conhecimento e a profissionalidade às práticas profissionais (Peduzzi, Norman, Germani, Silva, \& Souza, 2013), buscaremos, neste trabalho, discutir, à luz dos dispositivos postos em prática pelo projeto Bandeira Científica, os impactos da multi e interprofissionalidade/disciplinaridade na formação universitária, dando ênfase à formação em Psicologia.

\section{Operacionalização do projeto Bandeira Científica}

No caso do projeto Bandeira Científica, a interdisciplinaridade se revela na intensidade de trocas entre os estudantes de diferentes áreas do conhecimento e na integração dos saberes no interior de um mesmo projeto que envolve ensino, pesquisa e extensão. Tais trocas requerem reciprocidade, mutualidade, capacidade de adaptação, sensibilidade em relação às demais pessoas e uma postura de abertura para outros pontos de vista (Vilela \& Mendes, 2003). Essa postura envolve um questionamento intenso e contínuo entre as disciplinas, revelando limites e contradições, e é justamente desse encontro crítico que as barreiras - aparentemente intransponíveis - entre as disciplinas tornam-se permeáveis e porosas.

Para materializar o processo de construção do projeto, apresentaremos como o Bandeira se operacionaliza e as atividades, dispositivos e espaços que são construídos ao longo de cada ciclo. Um ciclo tem duração de um ano e meio e se divide em três fases: "preparação" (geralmente de fevereiro a novembro), "imersão" (duração de duas semanas) e "seguimento" (de janeiro até junho).

Dentro de cada uma dessas fases, são desenvolvidas atividades de modo a consolidar a parceria com o município escolhido e formar os estudantes que fazem parte do projeto (Figuras 1, 2 e 3).

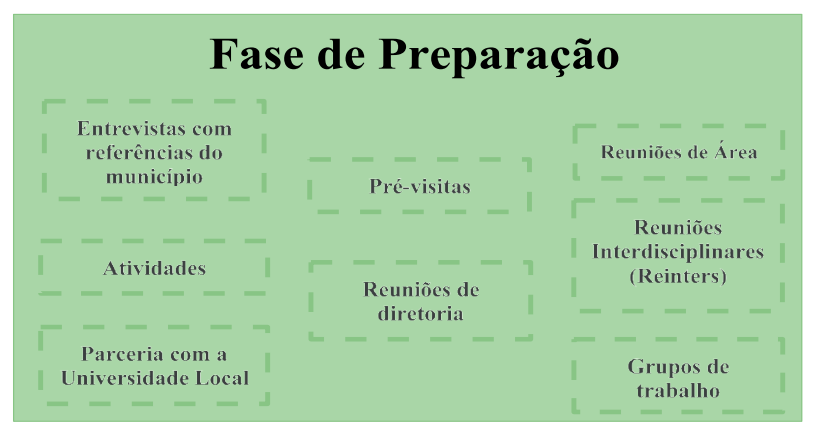

Figura 1

Atividades desenvolvidas na fase de preparação.

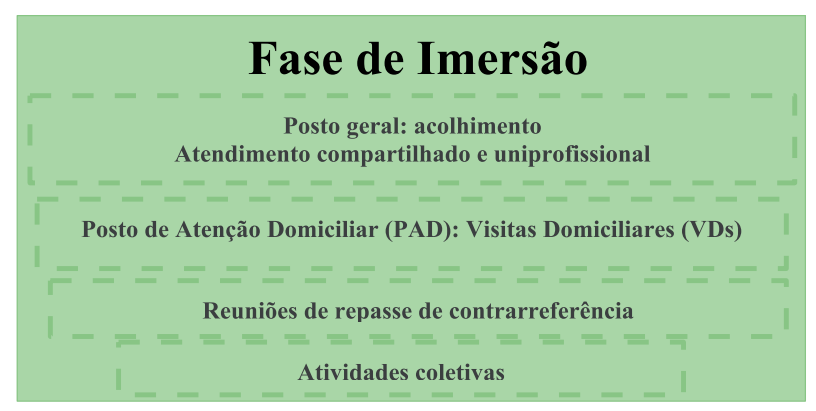

Figura 2.

Atividades desenvolvidas na fase de imersão.

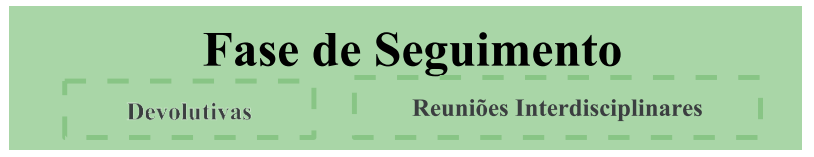

Figura 3.

Atividades desenvolvidas na fase de seguimento.

A fase de preparação tem como objetivo formar o coletivo da diretoria ${ }^{2}$, escolher e formalizar a parceria com a cidade, realizar a seleção de estudantes e supervisores das áreas participantes e, a partir de então, desenvolver atividades de formação em saúde e construir o que virá a ser realizado na cidade. Dentre essas atividades, há algumas específicas de cada área

\footnotetext{
${ }^{2}$ A diretoria é um coletivo constituído por estudantes que representam os cursos participantes. As pessoas que formam esse grupo já participaram de ao menos uma edição do projeto e têm como função cuidar dos aspectos organizativos, operacionais e de planejamento de todo o ciclo.
} 
e outras gerais. Durante os meses iniciais, são realizadas de três a quatro visitas à cidade (denominadas de pré-visitas), visando a consolidação da parceria e a investigação das demandas do município.

A fase da imersão compreende um período de cerca de duas semanas no mês de dezembro, no qual cerca de 200 participantes, ou seja, a maioria dos e das estudantes e discutidores ${ }^{3}$ de cada área, vão para a cidade para executar as intervenções planejadas na fase de preparação. Nesta fase, articulam-se atividades realizadas: a) no Posto de Atenção Domiciliar (PAD), responsável pelas Visitas Domiciliares (VDs) com ou sem a necessidade de trabalhos de adaptações, tais como manutenção de cadeira de rodas e de banho e confecção de dispositivos de auxílio, como bengalas e pranchas de comunicação; b) nas Atividades Coletivas (ACs) que focalizam ações de prevenção e promoção da saúde junto a grupos identificados nas pré-visitas, tais como encontros com agentes de saúde para discutir sobre suas ações, com grupo de jovens para debater o tema da sexualidade, atividades sobre a questão de gênero entre as mulheres da cidade e outras;c) nos Postos Gerais, em que acolhimentos e atendimentos são realizados por estudante de uma área (uniprofissional) ou compartilhados por estudantes de diferentes áreas (multiprofissional). Na edição de 2016/2017, sete cursos participaram dos atendimentos nos Postos Gerais: Farmácia, Fisioterapia, Fonoaudiologia, Medicina, Nutrição, Psicologia e Terapia Ocupacional.

São tecidas ações, também, que visam a aproximação com serviços da saúde (sobretudo com Unidades Básicas de Saúde) e da assistência social (Centro de Referência de Assistência Social e Centro de Referência Especializado de Assistência Social) do município, junto aos quais, no último dia da imersão, os casos atendidos são encaminhados e discutidos. Há também atividades desenvolvidas pelas áreas técnicas, centradas em questões de saneamento, reciclagem, acessibilidade, bem como voltadas à gestão e à participação social no Conselho Municipal de Saúde.

O período de seguimento acontece após a imersão, entre os meses de janeiro e junho, e tem como objetivo analisar as experiências vividas na cidade e os dados coletados, ponderando sobre como essas reflexões podem se articular com políticas públicas que caminhem na direção da promoção da saúde e fortalecimento de vínculos. São realizadas visitas (chamadas de pós-visitas) com objetivo de finalizar ações pendentes (entrega de óculos, por exemplo) e dar devolutivas específicas. Para o término do ciclo, cada área constrói um relatório cujos pontos principais compõem o relatório unificado entregue à gestão e aos profissionais atuantes no município.

Nesse desenho do funcionamento do projeto foram produzidos espaços que se configuram como dispositivos importantes na construção da interdisciplinaridade e que promovem mudanças significativas na formação e no trabalho dos estudantes que participam do projeto.

Os espaços que compreendemos como centrais na construção da interdisciplinaridade são as entrevistas com referências e lideranças comunitárias, o acolhimento, as VDs, as ACs e as Reuniões Interdisciplinares (Reinters).

\section{Entrevistas com referências e lideranças comunitárias}

A Psicologia inseriu essa atividade no projeto em 2006. Com o tempo, ela ganhou caráter interdisciplinar e interprofissional, contando com a participação de estudantes de Economia, Administração e Ciências Contábeis da FEA e, no último ciclo, da Farmácia e Odontologia. Essas entrevistas acontecem durante a fase de preparação, em uma pré-visita ao município, e têm como objetivo levantar os dados necessários para o reconhecimento das necessidades e demandas da cidade, buscando identificar as formas de relação que lá se configuram. Elas são realizadas por duplas de estudantes de diferentes cursos, com gestores, líderes comunitários, trabalhadores da rede municipal e outros munícipes indicados, fortalecendo a articulação do trabalho do projeto com a cidade. $\mathrm{O}$ fato de serem alunos da Universidade de São Paulo a realizar atividades relacionadas à saúde na cidade tenderia a criar a falsa ilusão de que o projeto teria como objetivo resolver alguns problemas por meio de ações pontuais, mas, por intermédio das entrevistas, podemos perceber que as questões presentes na cidade possuem uma dimensão histórico-social que transcende a gestão pública como um todo. As informações obtidas com as entrevistas são utilizadas para orientar toda a atuação do projeto no município, como, por exemplo, na elaboração das ACs.

\footnotetext{
${ }^{3}$ Discutidor é o termo utilizado no projeto para se referir aos profissionais que colaboram na elaboração das atividades propostas, realizam a supervisão técnica dos estudantes e respondem pelas condutas dadas durante os atendimentos, visitas domiciliares etc.
} 


\section{Atividades coletivas}

As ACs são atividades de prevenção e promoção de saúde direcionadas a grupos sociais identificados com ajuda das entrevistas. Esses grupos podem ser de profissionais do município - tais como grupos de educadores, agentes comunitários de saúde, profissionais de demais áreas - ou de moradores (adolescentes, mulheres, homens, idosos etc.). A partir da definição de quais grupos seria pertinente trabalhar conjuntamente, os estudantes de todas as áreas se dividem, com base em seus temas de interesse e não em especificidades de área, para construírem essas atividades durante a fase de preparação e organizarem sua implementação durante a imersão. Por exemplo, durante as entrevistas do ciclo 2016-17, muitos profissionais trouxeram a dificuldade de comunicação entre os diversos serviços da rede de saúde. Assim, os estudantes se propuseram a pesquisar e criar uma atividade direcionada aos trabalhadores da saúde que pudesse ser um espaço de discussão sobre estratégias de comunicação e matriciamento.

\section{Reuniões Interdisciplinares}

As Reinters são um espaço de discussão e organização do projeto para todos os participantes, a fim de promover formação continuada sobre interdisciplinaridade e interprofissionalidade. No ciclo 2016-17 houve sete encontros entre os estudantes e os discutidores de todas as áreas do projeto. Nesses, as diferentes concepções de saúde são debatidas e os rumos do projeto são discutidos, colocando em xeque os estereótipos e jogando luz sobre possíveis atuações conjuntas ao situar os estudantes na diversidade de pensamentos sobre cada tema de estudo e prática.

\section{Acolhimento}

Em edições anteriores do projeto, os postos de atendimento organizados durante a imersão recebiam encaminhamentos de pacientes realizados por profissionais de saúde da cidade para que fossem atendidos por alunos de alguma especialidade. Nos postos, as pessoas que chegavam passavam por uma triagem realizada pelos estudantes de medicina. Não era raro que os encaminhamentos fossem feitos para uma área, mas que, durante o atendimento, se percebesse que seria interessante haver outra área trabalhando junto. A discussão sobre a fragmentação operada em encaminhamentos de uma área a outra, de um especialista a outro, fazia-se presente na forma como o Bandeira Científica construía os postos de atendimento. Nas últimas duas edições do projeto, houve uma mudança significativa: há agora um momento de acolhimento ao paciente, conduzido por uma dupla de estudantes de diferentes áreas que, em conjunto com o munícipe, pensam como o posto de atendimento pode colaborar para $o$ atendimento das demandas de saúde, definindo prioridades a partir de uma perspectiva que visa a integralidade do cuidado.

\section{Visitas Domiciliares}

No projeto, essas visitas se estruturam por intermédio do PAD a partir dos encaminhamentos feitos pelos serviços de saúde do município. Quando foram implementadas no projeto, as VDs eram pensadas como forma de alcançar aquelas pessoas que não chegavam aos postos de atendimento e que, por vezes, também não acessavam os serviços do município, seja porque tinham mobilidade reduzida, seja porque moravam em povoados afastados da área urbana. A prática das VDs, entretanto, revelou que este é um dispositivo que potencializa a aproximação com o território, com a comunidade e com as pessoas da família que cuidam do munícipe, promovendo um diálogo mais intenso com as necessidades de saúde dos sujeitos e das comunidades. As pessoas deixam de ser indivíduos isolados e a dinâmica familiar se faz presente nas discussões e intervenções. As discussões de cada VD são realizadas em conjunto com várias áreas, levando-se em conta a demanda apresentada e a quantidade de pessoas (estudantes e discutidores) que podem ir à visita propriamente dita. A composição com outras áreas busca a construção de um modelo de visita pautado na clínica ampliada e um cuidado integral à saúde em que o foco é colocado no sujeito e não na doença (Brasil, 2007), exigindo um cuidado intenso no tocante à questão da ética profissional de estudantes e discutidores ao realizarem um trabalho que entra em contato com o usuário em sua residência. Uma das questões que passou a ser relevante nas discussões das visitas foi o trabalho dos cuidadores: quem são estes que estão envolvidos no cuidado da pessoa com deficiência ou da pessoa idosa? Como constituem a rede de apoio da pessoa da qual cuidam? Como se sentem ocupando essa função? Deparamonos com cuidadores adoecidos e, por vezes, invisibilizados, fazendo com que o dispositivo da VD trouxesse à tona desafios complexos presentes no processo de saúde-doença vivido pelos sujeitos. 


\section{Cenas interdisciplinares e o impacto na formação em psicologia}

Utilizando o conceito de cena elaborado por Paiva (1999), entendido como um momento singular no qual há um roteiro (papéis sociais e institucionais estabelecidos a priori), atores (sujeitos em relação) e um cenário (ambiente no qual a cena se dá), trabalharemos a partir de quatro situações vivenciadas pelos estudantes de Psicologia ao longo da experiência no projeto entre os anos de 2016 e 2017. Recolhemos elementos dessas situações que se confluem em relações cotidianas e são relevantes para discutir como o conceito de interdisciplinaridade se materializa em discursos, práticas e ações concretas a partir da dinâmica de um projeto de extensão universitária. Discorremos sobre situações em que a interdisciplinaridade possibilitou mudanças na formação e na construção do trabalho.

A primeira cena ocorreu em um momento de integração entre todas as áreas participantes do projeto: uma ReInter, que ocorre geralmente na vivência do Centro Acadêmico Oswaldo Cruz, na Faculdade de Medicina da Universidade de São Paulo. A proposta de uma dessas reuniões foi de que se realizasse uma atividade que provocasse pensar a visão que cada área tinha sobre si própria e sobre as outras. Os estudantes, reunidos com os colegas de sua própria área, deveriam eleger uma palavra que definisse sua própria especialidade e uma que definisse outra área pré-selecionada com base em um sorteio. $\mathrm{O}$ grupo da psicologia sorteou a área da Medicina e teve dez minutos para pensar em uma palavra que definisse o trabalho da medicina no projeto. A expressão escolhida para essa definição foi “Centralidade (?)”. Essa palavra e o ponto de interrogação a seguir entre parênteses permitiram problematizar a visão estereotipada muitas vezes atribuída à medicina, reforçando o modelo biomédico como sinônimo de atenção à saúde. O efeito dessa atribuição à área da medicina possuiu um efeito significativo de disparar uma discussão sobre como, muitas vezes, os estudantes de medicina sentem que essa centralidade é frequentemente atribuída pelas outras áreas, o que levantou o questionamento de relações de poder - aqui associadas à ideia de centralidade - que são sustentadas tanto por quem está no centro quanto por quem não está. Esse diálogo só pôde acontecer com a presença em corpo dos participantes do projeto, todos reunidos no prédio da própria Faculdade de Medicina.
A segunda situação diz respeito às entrevistas com as referências locais. Historicamente, elas eram feitas apenas pela equipe da Psicologia, que utilizava um roteiro semiestruturado padronizado. Mais tarde, os estudantes da FEA que também realizavam algumas atividades de cartografia do território durante viagens na pré-visita propuseram que as entrevistas pudessem ser uma atividade partilhada entre as equipes de psicologia e da FEA. Posteriormente, as áreas de Farmácia e de Odontologia se juntaram a esse processo. Portanto, tanto o questionário como o processo de análise das entrevistas realizadas, antes discutidos por estudantes de uma área, passaram a ser realizados com estudantes de diferentes áreas. A seguir, apresentaremos uma situação em que a presença dos estudantes da FEA foi decisiva para compor e variar as perguntas antes formuladas apenas pelos estudantes de Psicologia.

O fluxo de caixa da Secretaria de Saúde foi um tema bastante presente nas entrevistas realizadas com membros da equipe de gestão desse órgão do município. A princípio, discutir as finanças da cidade poderia não fazer muito sentido para uma equipe de estudantes de Psicologia, porém, durante a análise, percebemos o quanto esta é uma via de comunicação importante com os municípios. Foi possível compreender como, por meio da gestão do dinheiro, práticas e modelos de saúde são ou não legitimados e formas de viver são constituídas. Por intermédio das perguntas propostas pela FEA, analisou-se que a quantia de dinheiro que o município gastava com o transporte de pessoas a municípios vizinhos para consultas com especialistas de que a cidade não dispunha - em sua maioria dermatologistas e cardiologistas - era superior aos investimentos necessários para que a gestão contratasse esses profissionais e proporcionasse atendimento na própria cidade. Portanto, esse questionamento disparou reflexões importantes para ampliar formas de cuidar.

A terceira cena que iremos descrever se deu em uma VD a uma senhora que havia recentemente sofrido um Acidente Vascular Encefálico (AVE). A visita, previamente planejada de acordo com as demandas dos sujeitos que chegam até o projeto, inicialmente teve como objetivo central a adaptação de recursos e orientações para a reabilitação da senhora. Estavam presentes alunas da Fisioterapia e da Terapia Ocupacional, a discutidora das VDs e do PAD e um estudante de Psicologia. A presença do estudante de Psicologia não era prevista nessas visitas domiciliares, que demandam saberes específicos para trabalhar com pessoas com 
dificuldade de locomoção. Contudo esse estudante, por ter acompanhado a estruturação do PAD e a configuração das VDs, interessou-se por participar dessa ação.

$\mathrm{Na}$ casa, habitavam a senhora e seu companheiro, também idoso e seu único cuidador. Ele também apresentava problemas de saúde, que influíam em seu papel de cuidador: tinha uma hérnia notável que lhe causava muita dor, principalmente ao carregar e auxiliar sua esposa em alguns movimentos. A visita havia sido planejada para realizar orientações e adaptações que pudessem auxiliá-los e melhorar o cotidiano de modo geral. A possibilidade de um estudante compor um espaço comum de trabalho nas VDs, mesmo sem um propósito específico do que fazer naquele ambiente, possibilitou um espaço de discussão sobre o próprio dispositivo das visitas. Da pergunta "o que eu faço aqui?" derivou a pergunta "o que fazemos aqui?", que possibilitou um espaço para reflexão e consideração de questões que não estavam associadas ao propósito da VD - como, por exemplo, a saúde do cuidador.

A quarta e última cena se deu em um atendimento compartilhado entre as áreas da psicologia e da nutrição durante as atividades no posto de atendimento. Importante ressaltar que atender de forma compartilhada é uma conquista recente do projeto e tem gerado a possibilidade de composição de diferentes formas de cuidar. Inicialmente, o pedido por atendimento havia chegado apenas à área da Nutrição: era a situação de uma mulher obesa que desejava orientações e cuidados referentes à obesidade. Contudo, com o acolhimento inicial e após uma conversa com os discutidores dessas duas áreas, decidiu-se que um estudante de Psicologia participaria do atendimento para ajudar a compreender melhor dúvidas deflagradas pelo modo como a senhora se apresentou durante a primeira conversa. Durante o atendimento compartilhado, foram feitas algumas perguntas acerca da rotina alimentar e do funcionamento do sistema digestivo. A indagação sobre outras rotinas - o trabalho, as pessoas com as quais se relacionava e vivia e os momentos em que fazia as refeições - foi disparadora para a senhora contar sobre o tempo que reservava para as refeições e sobre a rotina com suas filhas. Ao falar delas, relatou o abandono que sofrera de um ex-parceiro e a culpa por ter se envolvido com esse homem. As misturas presentes entre as questões físicas, alimentares e afetivas foram ouvidas por ambos estudantes, que, juntos, souberam deixar espaço aberto para a mulher falar sobre esse abandono e as marcas produzidas. Provavelmente, nem o estudante de Psicologia, nem a estudante de nutrição, se tivessem realizado os atendimentos separadamente, poderiam compreender a relação entre as dimensões física e psíquica na vida daquela paciente. $\mathrm{O}$ encontro entre aquelas três pessoas - a paciente e os estudantes de psicologia e de nutrição - possibilitou repensar a tão naturalizada separação cartesiana entre as profissões.

Durante a formação em Psicologia, em muitas disciplinas e práticas, embora a multideterminação seja tomada como princípio para analisar os fenômenos, há uma falta de trabalhos e experiências em que haja composição de conhecimentos produzidos por diferentes áreas. Isso intensifica uma tendência em que os estudantes julgam e criticam aquilo que, em suas análises, faltaria aos trabalhos das outras áreas. Durante um certo tempo, os estudantes de Psicologia que participaram do projeto Bandeira Científica mantinham essa forma de pensar: parecia que às outras áreas faltariam reflexões presentes na formação em Psicologia. No entanto, na verdade, o problema refere-se a algo a que todos estão submetidos: um tipo de formação em que o saber se produz de maneira fragmentada e isolada. Como apresentamos, o fato de o grupo da Psicologia atribuir centralidade ao grupo da Medicina em uma das ReInters é uma evidência da força presente na própria construção histórica e cotidiana dessa centralidade.

Cuidar dessa tendência julgadora é tarefa difícil. Os estudantes de Psicologia que participam do projeto têm reuniões semanais de quatro horas, realizam supervisões mensais, conversam com diferentes professores para aprofundarem temas diversos que são trabalhados nas atividades coletivas durante a imersão (trabalho, sexualidade, educação, saúde, juventude etc.), discutem textos e participam de projetos de pesquisa e de extensão em que aprofundam seus conhecimentos $^{4}$. Nesses espaços de discussão e formação há o cuidado para se criar estratégias de composição de trabalhos com as diferentes áreas.

\footnotetext{
${ }^{4}$ Algumas discussões presentes neste artigo foram desenvolvidas em um dos projetos acadêmicos aos quais os estudantes do Bandeira se vincularam. De setembro de 2016 a abril 2017, duas alunas do grupo da Psicologia no projeto Bandeira Científica, Débora Song Shimba e Kelly Tomie Taniguchi, foram bolsistas no projeto intitulado "Do encontro com as referências de uma cidade ao contato com a população: possibilidades de intervenções psicossociais no Projeto Bandeira Científica”, com bolsa pelo Fundo de Cultura e Extensão Universitária da USP e orientação de Adriana Marcondes Machado, do IPUSP. Participaram como voluntários no projeto Bruna Caroline Oliveira de Souza, Fernanda de Jesus Ligeiro Braga, Gabriel Rodrigues Mardegan, Jéssica Aparecida da Silva, José Barbosa de Araújo Silva Júnior, Rodolfo Luis Almeida Maia e Tales de Areco Chaves.
} 
Ressalta-se que, hoje, o caráter interdisciplinar nas práticas do Bandeira Científica é efeito de mudanças que se deram durante os anos. Por exemplo, um dos elementos que os estudantes tiveram que enfrentar quando implantaram o acolhimento, realizado por uma dupla de estudantes de diferentes áreas, foi a certeza da dúvida em relação a como decidir qual seria o melhor atendimento para a pessoa que estava sendo ouvida. Uma dúvida que não é falta de certeza, mas sim expressão de que as coisas se misturam, de que a vida nunca é algo que uma especialidade explica. Como afirma Adriana Marcondes Machado, "Tratar a doença não é tratar o sintoma. O sintoma habita uma vida que precisa ser pensada" (Machado, 2010, p. 80). Esse tipo de estratégia em que, na mistura, ouvindo os outros, definem-se as direções a serem adotadas fortalece e implica a todos nas decisões tomadas. Durante o acolhimento, começaram a acontecer situações que passavam a demandar diferentes encaminhamentos: às vezes, algo se dava no acolhimento e não havia mais a necessidade de realizar um encaminhamento para uma especialidade, outras vezes se decidia que seria importante haver um atendimento compartilhado, em outras deflagrava-se algo específico, e, em alguns momentos, a dúvida sobre o que fazer exigia mais conversas. Como descrito, a partir do acolhimento realizado com a mulher que queria cuidar da obesidade, foi decidido haver um atendimento compartilhado com estudantes de psicologia e de nutrição. Foi com a participação dos estudantes da FEA nas entrevistas com as referências da cidade que os estudantes de Psicologia consideraram algumas dimensões econômicas na constituição das formas de viver e de cuidar. Se, por um lado, sabemos que as formas de viver são construídas também no enredamento de questões econômicas, calcular os gastos para se ter o transporte de munícipes para outra cidade em comparação com a contratação de dois especialistas na própria cidade, podendo priorizar e fortalecer os serviços da atenção básica, ajudou a colocarmos em análise as forças em jogo quando essas decisões são tomadas. Também a ida imprevista do estudante de Psicologia a uma determinada Visita Domiciliar ressaltou a abertura do projeto para outras reflexões em histórias intensas que demandam orientações e adequações.

Os estudantes chegam ao projeto buscando suas especificidades, mas aquilo que vai se definindo como o que seria específico da psicologia, da nutrição, da fisioterapia, da medicina, da odontologia, da veterinária, da fonoaudiologia, da farmácia, da economia, da terapia ocupacional, da saúde pública, da engenharia civil, mecânica e ambiental (áreas presentes na edição do projeto de 2016-2017) é construído na relação com as outras áreas. Essas especificidades exigem rupturas em relação ao que é definido anteriormente, para que cada área possa manter a criação de seu fazer. Em alguns momentos, seria entendido que uma pessoa chorando no posto de atendimento seria algo sobre o qual apenas os estudantes de Psicologia teriam condições de suportar e agir. Por um lado, isso é verdade: em nossa formação, enfrentamos muitas situações de sofrimento em que o choro, o desânimo e o desespero aparecem no relato que as pessoas fazem de si enquanto as ouvimos. Contudo, o que o projeto nos ensina é que esse tipo de segmentação - a questão da alimentação seria da nutrição; a doença, da medicina; a tristeza, da psicologia; a fala, da fonoaudiologia e assim por diante - precisa ser analisada e transformada para se construir o trabalho e se formar.

\section{Considerações finais}

Compreendemos que a intensa qualidade do projeto Bandeira Científica é sua capacidade de variar. Além de mudanças em cada edição do projeto - as cidades são diferentes, sua geografia produz várias possibilidades de ação e as pessoas com as quais conversamos trazem de forma singular as experiências vividas na cidade -, há uma variação longitudinal, isto é, as propostas do projeto variam no decorrer do tempo. Essas variações no projeto mantêm a direção ética do cuidado e implicam uma abertura ao outro como estratégia para "romper as amarras que impedem a potencialização da existência que se cristaliza quando colocamos os fenômenos da vida em uma cadeia rigorosa de causas e efeitos" (Machado, 2017, p. 34). As amarras são legitimadas nas práticas cotidianas, nas relações de poder e saber das quais fazemos parte, e romper com elas é função importante em uma formação que se pretende crítica.

A potência inventiva (e singular) de cada um dos estudantes do projeto é reforçada pelas experiências interdisciplinares e interprofissionais em que o outro é aquele que possibilita sermos diferentes do que nos tornamos. E o que nos tornamos requer espreita, pois isso é engendrado em relações de poder e saber presentes por meio das quais tratamos aqueles que atendemos como se fossem objetos das intervenções, como pessoas a serem 
julgadas e em relação às quais pretenderíamos ensinar. A presença das experiências interdisciplinares, ao nos forçar dialogar, incentiva o rompimento dessas amarras.

Vale ressaltar que o saber interdisciplinar e interprofissional não nasce espontaneamente, mas é trabalhado e cultivado ao longo de todo o ciclo. Todas as atividades interdisciplinares desenvolvidas em cada uma das fases do projeto não se encerram em si mesmas. Se o exercício de interdisciplinaridade começa concretamente, por exemplo, por meio das ReInters, ele se intensifica e se torna mais frequente à medida que atravessa os demais dispositivos: os grupos de trabalho, as ACs, os atendimentos, as VDs e a devolutiva. Busca-se, assim, que as práticas e discussões realizadas no projeto criem uma tessitura cuja costura é feita pela interdisciplinaridade.
É possível observar que o inter vai se intensificando a partir da possibilidade de momentos de conflito entre os saberes que passam por tensões e rupturas para que soluções coletivas sejam construídas. Fugir da sobreposição e da fragmentação exige dos/das estudantes a criação de estratégias que criem composições entre os saberes de diferentes áreas.

Logo após o término de um ciclo do projeto, mas sobretudo após a imersão, os participantes vivem as marcas dos esforços necessários na criação do trabalho. A composição de saberes e a interdisciplinaridade, da qual falamos neste artigo, bem como o trabalho em equipe e no coletivo, exigem reformulações, mediações, desconstruções e rupturas pouco presentes nos cursos de graduação. Por isso, afirmamos a potência desse projeto interdisciplinar e interprofissional em suas possibilidades de aprendizagem, formação e intervenção.

\section{Referências}

Brasil. (1988). Constituição da República Federativa do Brasil de 1988. Brasília, DF: Presidência da República. http://www.planalto.gov.br/ccivil_03/constituicao/constituicaocompilado.htm

Brasil. (1990). Lei $n^{\circ}$ 8080, de 19 de setembro de 1990. Dispõe sobre as condições para a promoção, proteção e recuperação da saúde, a organização e o funcionamento dos serviços correspondentes e dá outras providências. Brasília, DF: Presidência da República.

Brasil. (2007). Secretaria de Atenção à Saúde. Política nacional de humanização da saúde: Documento base (4a ed.). Brasília, DF: Ministério da Saúde.

Ceccim, R. B., \& Feuerwerker, L. C. M. (2004). O quadrilátero da formação para aárea da saúde: Ensino, gestão, atenção e controle social. Physis - Revista de Saúde Coletiva, 14(1), 41-65. https://doi.org/10.1590/S0103-73312004000100004

Dejours, C. (1986). Por um novo conceito de saúde. Revista Brasileira de Saúde Ocupacional, 14(54), 7-11.

Dimenstein, M. \& Macedo, J. P. (2012). Formação em psicologia: Requisitos para atuação na atenção primária e psicossocial. Psicologia: Ciência e Profissão, 32(n. esp.), 232-245. https://doi.org/10.1590/S1414-98932012000500017

Gomes, R. \& Deslandes, S. F. (1994). Interdisciplinaridade na saúde pública: Um campo em construção. Revista Latino-americana de Enfermagem, 2(2), 103-114. https://doi.org/10.1590/S0104-11691994000200008.

Gusdorf, G. (1976). Prefácio. In H. Japiassu, Interdisciplinaridade e patologia do saber (pp. 8-26). Rio de Janeiro, RJ: Imago.

Japiassu, H. (1976). Interdisciplinaridade e patologia do saber. Rio de Janeiro, RJ: Imago.

Machado, A. M. (2010). Oportunidade de luta. In A. J. M. Leite \& J. M. Coelho (Orgs.), Você pode me ouvir, Doutor? Cartas para quem escolheu ser médico (pp. 69-81). Campinas, SP: Saberes Editora.

Machado, A. M. (2017). A experiência sensível e a constituição do problema em um trabalho de intervenção. In A. M. Machado, A. B. C. Lerner \& P. F. Fonseca (Orgs.), Concepções e proposições em Psicologia e Educação (pp. 29-48). São Paulo, SP: Blucher.

Luz, M. (2009). Complexidade do campo da saúde coletiva: Multidisciplinaridade, interdisciplinaridade, e transdisciplinaridade de saberes e práticas: Análise sócio-histórica de uma trajetória paradigmática. Saúde e Sociedade, 18(2), 304-311. http://dx.doi.org/10.1590/S0104-12902009000200013

OrganizaçãoMundialdaSaúde.(1946).ConstituiçãodaOrganizaçãoMundialdaSaúde.USP.http://www.direitoshumanos. usp.br/index.php/OMS-Organização-Mundial-da-Saúde/constituicao-da-organizacao-mundial-da-saudeomswho.html 
Paiva, V. (1999). Cenas sexuais, roteiros de gênero e sujeito sexual. In R. M. Barbosa \& R. Parker (Org.), Sexualidades pelo avesso: Direitos, identidades e poder (pp. 247-269). São Paulo, SP: Editora 34.

Peduzzi, M., Norman, I. J., Germani, A. C. C. G., Silva, J. A. M., \& Souza, G. C. (2013). Educação Interprofissional: Formação de profissionais de saúde para o trabalho em equipe com foco nos usuários. Revista da Escola de Enfermagem da USP, 47(4), 977-983. https://doi.org/10.1590/S0080-623420130000400029

Vilela, E. M., \& Mendes, I. J. M. (2003). Interdisciplinaridade e saúde: Estudo bibliográfico. Revista Latino-Americana de Enfermagem, 11(4), 525-531. https://doi.org/10.1590/S0104-11692003000400016

\section{Adriana Marcondes Machado}

Docente do Departamento de Psicologia da Aprendizagem, do Desenvolvimento e da Personalidade do Instituto de Psicologia da Universidade de São Paulo (USP), São Paulo - SP. Brasil.

E-mail: adrimarcon@uol.com.br

(i) https://orcid.org/0000-0002-5513-8723

\section{Fernanda de Jesus Ligeiro Braga}

Psicóloga com pós-graduação lato sensu em Rede de Atenção Psicossocial pela Universidade Federal de São Paulo (UNIFESP), Santos - SP. Brasil.

E-mail: braga_fernanda@outlook.com

(1) https://orcid.org/0000-0003-2796-7644

\section{Rodolfo Luis Almeida Maia}

Psicólogo, Mestre e Doutorando do Programa de Pós-Graduação em Psicologia Social da Universidade de São Paulo (USP), São Paulo - SP. Brasil.

E-mail: rodolfo.maia09@gmail.com

(1) https://orcid.org/0000-0003-0414-3474

\section{Débora Song Shimba}

Psicóloga Residente Multiprofissional em Saúde Mental pela Universidade Estadual de Campinas (UNICAMP), Campinas - SP. Brasil.

E-mail: debora.song.shimba@gmail.com

(1) https://orcid.org/0000-0003-0750-0414

\section{Gabriel Rodrigues Mardegan}

Psicólogo Residente Multiprofissional em Saúde da Família pela Escola Nacional de Saúde Pública/Fundação Oswaldo Cruz (ENSP/FIOCRUZ), Rio de Janeiro - RJ. Brasil.

E-mail: gabriel.r.mardegan@gmail.com

(1) https://orcid.org/0000-0002-2389-003X

\section{Bruna Caroline Oliveira de Souza}

Psicóloga Residente Multiprofissional em Oncologia Pediátrica pela Universidade Federal de São Paulo (UNIFESP), São Paulo - SP. Brasil.

E-mail: bru.cosouza@gmail.com

(1) https:// orcid.org/0000-0002-4449-1302

\section{Jéssica Aparecida da Silva}

Psicóloga e Bacharela em Psicologia pela Universidade de São Paulo, São Paulo - SP. Brasil.

E-mail: jessaparecidadasilva@gmail.com

(1) https://orcid.org/0000-0002-8976-6349 
Endereço para envio de correspondência:

Universidade de São Paulo, Instituto de Psicologia, Departamento de Psicologia da Aprendizagem, do Desenvolvimento e da Personalidade. Av. Prof. Mello Moraes, 1721, bloco A, Cidade Universitária. CEP: 05508900. São Paulo - SP. Brasil.

Recebido 12/09/2018

Aceito 21/08/2019

Received 09/12/2018

Approved 08/21/2019

Recibido 12/09/2018

Aceptado 21/08/2019

Como citar: Machado, A. M., Braga, F. J. L., Maia, R. L. A, Shimba, D. S., Mardegan, G. R., Souza, B. C. O., \& Silva, J. A. (2020). Projeto Bandeira Científica: uma extensão interdisciplinar com impactos na formação em Psicologia. Psicologia: Ciência e Profissão, 40, 1-12. https://doi.org/10.1590/1982-3703003213952

How to cite: Machado, A. M., Braga, F. J. L., Maia, R. L. A, Shimba, D. S., Mardegan, G. R., Souza, B. C. O., \& Silva, J. A. (2020). Bandeira Científica Project: an interdisciplinary extension course with impacts on the professional training in Psychology. Psicologia: Ciência e Profissão, 40, 1-12. https://doi.org/10.1590/1982-3703003213952

Cómo citar: Machado, A. M., Braga, F. J. L., Maia, R. L. A, Shimba, D. S., Mardegan, G. R., Souza, B. C. O., \& Silva, J. A. (2020). Proyecto Bandeira Científica: una extensión interdisciplinaria con efectos en la formación en psicología. Psicologia: Ciência e Profissão, 40, 1-12. https://doi.org/10.1590/1982-3703003213952 